\title{
Mapping of Surface-Exposed Epitopes of In Vitro and In Vivo Aggregated Species of Alpha-Synuclein
}

\author{
Leire Almandoz-Gil ${ }^{1}$ • Veronica Lindström ${ }^{1} \cdot$ Jessica Sigvardson $^{2}$ • \\ Philipp J. Kahle ${ }^{3,4} \cdot$ Lars Lannfelt $^{1} \cdot$ Martin Ingelsson $^{1} \cdot$ Joakim Bergström $^{1}$
}

Received: 1 July 2016/ Accepted: 16 December 2016/Published online: 27 December 2016

(c) The Author(s) 2016. This article is published with open access at Springerlink.com

\begin{abstract}
Aggregated alpha-synuclein is the main component of Lewy bodies, intraneuronal deposits observed in Parkinson's disease and dementia with Lewy bodies. The objective of the study was to identify surface-exposed epitopes of alpha-synuclein in vitro and in vivo formed aggregates. Polyclonal immunoglobulin Y antibodies were raised against short linear peptides of the alpha-synuclein molecule. An epitope in the N-terminal region (1-10) and all C-terminal epitopes (90-140) were found to be exposed in an indirect enzyme-linked immunosorbent assay (ELISA) using recombinant monomeric, oligomeric, and fibrillar alpha-synuclein. In a phospholipid ELISA, the $\mathrm{N}$-terminus and mid-region of alpha-synuclein (i.e., 1-90) were associated with phosphatidylserine and thus occluded from antibody binding. The antibodies that reacted most strongly with epitopes in the in vitro aggregates (i.e., 1-10 and epitopes between positions 90-140) also labeled alphasynuclein inclusions in brains from transgenic (Thy-1)$\mathrm{h}[\mathrm{A} 30 \mathrm{P}]$ alpha-synuclein mice and Lewy bodies and Lewy neurites in brains of patients with alpha-synucleinopathies. However, differences in reactivity were observed with the C-terminal antibodies when brain tissue from human and transgenic mice was compared. Taken together, the study
\end{abstract}

Joakim Bergström

joakim.bergstrom@pubcare.uu.se

1 Department of Public Health and Caring Sciences/Molecular Geriatrics, Uppsala University, Uppsala, Sweden

2 BioArctic, Stockholm, Sweden

3 Laboratory of Functional Neurogenetics, Department of Neurodegeneration, Hertie Institute for Clinical Brain Research, University of Tübingen, Tübingen, Germany

4 German Center of Neurodegenerative Diseases, Tübingen, Germany shows that although similar epitopes are exposed in both in vitro and in vivo formed alpha-synuclein inclusions, structural heterogeneity can be observed between different molecular species.

Keywords Parkinson's disease - Dementia with Lewy bodies · Alpha-synuclein · Epitope mapping

\section{Introduction}

The alpha-synucleinopathies are a subset of neurodegenerative diseases that include Parkinson's disease (PD), dementia with Lewy bodies (DLB), multiple system atrophy (MSA), and the Lewy body variant of Alzheimer's disease (Goedert 2001). The common pathological feature of the alpha-synucleinopathies is the presence of insoluble cytoplasmic aggregates of alpha-synuclein, termed Lewy bodies and Lewy neurites (Spillantini et al. 1997). In PD, the inclusions are mainly found in dopaminergic neurons in the substantia nigra and other subcortical regions, while in DLB, they are also located in the cerebral cortex (Spillantini et al. 1997, 1998). In MSA, the aggregates are predominantly found in oligodendrocytes and are then referred to as glial cytoplasmic inclusions (Papp et al. 1989).

Alpha-synuclein consists of three distinct structural domains: a lipid-interacting amino-terminus (1-60), a hydrophobic mid-region (61-95), and an acidic carboxylterminus with a random coil structure (96-140) (George et al. 1995). It has been believed that alpha-synuclein mainly exists as an intrinsically disordered protein, which adopts an alpha-helical structure upon binding to lipids via its N-terminus and central region (Davidson et al. 1998). 
The physiological function of alpha-synuclein remains largely unknown, but increasing evidence suggest that it is involved in neurotransmitter release (Abeliovich et al. 2000; Nemani et al. 2010). For example, alpha-synuclein can promote the formation of the soluble $N$-ethylmaleimide-sensitive factor attachment protein receptor (SNARE) complex by binding phospholipids in the cell membrane with its $\mathrm{N}$-terminus and synaptobrevin- 2 with its C-terminus (Burré et al. 2010).

Further implicating alpha-synuclein misfolding in the pathogenesis of neurodegenerative diseases, duplications and triplications of the alpha-synuclein gene (Singleton et al. 2003; Ibáñez et al. 2004), as well as six different point missense mutations have been found to cause either PD or DLB. All the identified point mutations are located in the N-terminal region of the molecule: A53T (Polymeropoulos et al. 1997), A30P (Krüger et al. 1998), E46K (Zarranz et al. 2004), H50Q (Appel-Cresswell et al. 2013), G51D (Lesage et al. 2013), and A53E (Pasanen et al. 2014).

In the alpha-synucleinopathies, alpha-synuclein forms oligomers and protofibrils of increasing sizes, ultimately leading to insoluble fibrils, which constitute the main component of the Lewy body. Mounting evidence suggests that the oligomers are the most neurotoxic molecular species, as they have been shown to cause cytotoxicity both in vitro and in vivo (Danzer et al. 2007; Outeiro et al. 2008; Karpinar et al. 2009; Winner et al. 2011). However, it has not been fully elucidated which parts of the protein are involved in the aggregation process and how well alphasynuclein aggregates generated in vitro resemble in vivo formed inclusions.

So far, a pair of studies have been performed using antibodies recognizing linear epitopes to characterize structural properties of alpha-synuclein inclusions in the brains of diseased patients (Giasson et al. 2000; Duda et al. 2002). However, no study has systematically compared surface-exposed epitopes of in vitro and in vivo formed alpha-synuclein aggregates. Here, we raised polyclonal immunoglobulin Y (IgY) antibodies against short linear epitopes spanning most of the molecule. These antibodies were used to determine the exposed epitopes of alphasynuclein monomers and fibrils generated in vitro, as well as inclusions in brain tissue sections from a transgenic (Thy-1)-h[A30P] alpha-synuclein mouse model and from patients with alpha-synucleinopathies.

\section{Materials and Methods}

\section{Peptide Generation}

The immunizing peptides (10-11 amino acids) were custom synthetized at Capra Science Antibodies (Ängelholm,
Sweden), and the molecular weight of the peptides was confirmed by mass spectral analysis. The peptides had a purity of about $90 \%$ as determined by analytical HPLC. The longer peptides (19-26 amino acids) were custom synthetized at KJ Ross Petersen Aps (Copenhagen, Denmark).

\section{Antibody Production}

Polyclonal IgY antibodies were custom manufactured at Capra Science Antibodies (Ängelholm, Sweden). In short, the synthetic peptides were linked to keyhole limpet hemocyanin and two peptides $(100 \mu \mathrm{g}$ each) per chicken were injected together with Freund's complete adjuvant (week 0). Two additional boosts (with $100 \mu \mathrm{g}$ peptide) with Freund's incomplete adjuvant were performed (weeks 4 and 8). Eggs were then collected and the $\operatorname{IgY}$ fraction was purified, followed by an affinity purification step where the antigens were covalently immobilized on an agarose gel and the antibodies were eluted at $\mathrm{pH} 2.7$.

\section{Production and Purification of Recombinant Alpha- Synuclein}

Recombinant wild-type (wt) alpha-synuclein was cloned, expressed, and purified as previously described (Näsström et al. 2011). Mutant alpha-synuclein (A30P, E46K and A53T) was purchased from rPeptide (Athens, GA).

\section{Generation of Alpha-Synuclein Oligomers and Fibrils}

To generate 4-hydroxy-2-nonenal (HNE)-induced alphasynuclein oligomers, alpha-synuclein $(140 \mu \mathrm{M})$ in $50 \mathrm{mM}$ sodium phosphate buffer $\mathrm{pH} 7.4$ was mixed with HNE (Cayman Chemical, Ann Arbor, MI) to a final molar ratio of 30:1 (HNE:alpha-synuclein). The samples were incubated quiescently at $37{ }^{\circ} \mathrm{C}$ for $24 \mathrm{~h}$, and unbound aldehyde was removed by a Zeba spin desalting column (Thermo Fisher Scientific, Waltham, MA) according to the manufacturer's instructions. To generate fibrils, wt and mutant alpha-synuclein $(140 \mu \mathrm{M})$ were incubated in Tris buffered saline (TBS) pH 7.4 in a non-binding polystyrene 96-well plate with agitation for 7 days at $37^{\circ} \mathrm{C}$. The alpha-synuclein fibrils were first pelleted by centrifugation at $16,000 \times g$, then re-suspended and washed in TBS and pelleted again by centrifugation. This procedure was performed twice. The fibrillar content of such samples has been verified by atomic force microscopy earlier (Näsström et al. 2011), but to confirm the presence of fibrils in the pelleted material, $1 \mu \mathrm{l}$ of sample was dried on a glass slide that was stained with Congo red (Sigma-Aldrich, St. Louis, 
MO). All fibrillar samples exhibited typical apple-green birefringence when viewed under polarized light.

\section{Indirect Enzyme-Linked Immunosorbent Assay (ELISA)}

A 96-well high-binding polystyrene plate (Corning Inc., Corning, NY) was coated with $50 \mathrm{ng}$ antigen (synthetic peptides, monomeric or fibrillar alpha-synuclein) and was incubated overnight at $4{ }^{\circ} \mathrm{C}$. After blocking for $2 \mathrm{~h}$ with phosphate buffered saline (PBS) supplemented with $1 \%$ bovine serum albumin (BSA, Sigma-Aldrich) and 0.15\% kathon (Dow Chemical Company, Midland, MI), the antibodies were incubated at a concentration of $0.5 \mu \mathrm{g} / \mathrm{ml}$ for $1 \mathrm{~h}$ in PBS with $0.1 \%$ BSA and $0.05 \%$ Tween-20 (SigmaAldrich). An HRP-bound secondary anti-chicken goat antibody (Jackson ImmunoResearch Laboratories Inc., West Grove, PA) was incubated for $1 \mathrm{~h}$ at $0.08 \mu \mathrm{g} / \mathrm{ml}$ in the PBS buffer used for the primary antibody step. The reaction was developed with $100 \mu \mathrm{K}$ K-Blue Aqueous TMB substrate (Neogen Corporation, Lansing, MI) and stopped with the addition of $100 \mu \mathrm{l} 1 \mathrm{M}$ sulfuric acid (SigmaAldrich). Between every step, the wells were washed five times with PBS with $0.1 \%$ Tween 20 and $0.0075 \%$ kathon. The absorbance was measured at $450 \mathrm{~nm}$ using an Infinite M200 Pro microplate reader (Tecan, Männedorf, Switzerland). The signal of the blank (no coated antigen) was subtracted from the sample signals.

\section{Phospholipid ELISA}

1,2-Dioleoyl-sn-glycero-3-phospho-L-serine (DOPS) ELISA Snoopers $^{\mathrm{TM}}$ (Avanti Polar Lipids, Alabaster, AL) 8-well strips were blocked with $200 \mu \mathrm{l} /$ well of blocking buffer [1\% fatty acid-free BSA (Sigma-Aldrich) in PBS] at $4{ }^{\circ} \mathrm{C}$ overnight. Then, alpha-synuclein samples (50 ng/well) were incubated in PBS for $3 \mathrm{~h}$ with gentle shaking at room temperature and washed four times with PBS. The antibodies were incubated at a concentration of $0.5 \mu \mathrm{g} / \mathrm{ml}$ in blocking buffer for $1 \mathrm{~h}$. Following three PBS washes, an HRP-bound secondary anti-chicken antibody (Jackson ImmunoResearch Laboratories Inc.) was incubated for $1 \mathrm{~h}$ at $0.08 \mu \mathrm{g} / \mathrm{ml}$ in blocking buffer. After three PBS washes, the reaction was developed with TMB substrate (Neogen Corporation) and $1 \mathrm{M}$ sulfuric acid (Sigma-Aldrich). The absorbance was measured at $450 \mathrm{~nm}$ using an Infinite M200 Pro microplate reader (Tecan). The signal of the blank (no antigen) was subtracted from the sample signal.

\section{Transgenic Alpha-Synuclein Mouse Model}

Formalin-fixed and paraffin-embedded brain tissues from homozygous (Thy-1)-h[A3OP] alpha-synuclein mice
(Kahle et al. 2000) were used $(n=4 ; 16,18,19$, and 22 months of age). The tissue was sagittally sectioned $(3 \mu \mathrm{m})$. Brain tissue from wt mice $(\mathrm{C} 57 \mathrm{BL} / 6)$ was used as a negative control (18 months of age). All animal procedures with the (Thy-1)-h[A3OP] alpha-synuclein mouse have been approved by the regional board of Tübingen, Germany. Animal procedures with the wt mice have been approved by the animal ethics committee of Uppsala, Sweden.

\section{Human Brain Tissue}

The brain samples were obtained from The Netherlands Brain Bank (NBB), Netherlands Institute for Neuroscience, Amsterdam (open access: www.brainbank.nl), project number 848. All the materials were collected from donors from whom a written informed consent for a brain autopsy and the use of the material and clinical information for research purposes had been obtained by the NBB. Substantia nigra samples from four patients [one PD, one DLB, and two Parkinson's disease with dementia (PDD)] and one neurologically normal control were used (Table 1).

\section{Immunohistochemistry of Mouse and Human Brain Tissue}

Paraffin sections were deparaffinized through ethanol baths of decreasing concentration (99.9-70\%) and then washed with distilled water. The sections were pretreated with proteinase K (Life Technologies, Carlsbad, CA) at $50 \mu \mathrm{g} /$ $\mathrm{ml}$ in a buffer containing $10 \mathrm{mM}$ Tris- $\mathrm{HCl}, 100 \mathrm{mM} \mathrm{NaCl}$, $0.1 \%$ Nonidet-P40 (United States Biochemical Corporation, Cleveland, $\mathrm{OH}$ ) at $\mathrm{pH} 7.8$ and $37^{\circ} \mathrm{C}$ for $5 \mathrm{~min}$. Additionally, the human tissue was microwaved in preheated $25 \mathrm{mM}$ citrate buffer for $15 \mathrm{~s}$ and allowed to cool down at room temperature for $40 \mathrm{~min}$. All sections were then permeabilized with $0.4 \%$ Triton $\mathrm{X}-100$ (SigmaAldrich) in TBS for $10 \mathrm{~min}$ and treated with $0.3 \% \mathrm{H}_{2} \mathrm{O}_{2}$ for 5 min to block endogenous peroxidase reactivity. The sections were blocked with Background Sniper (Biocare Medical, Concord, CA) and incubated at $4{ }^{\circ} \mathrm{C}$ overnight

Table 1 Summary of information of the patient material used in the study

\begin{tabular}{llllll}
\hline Case\# & 1 & 2 & 3 & 4 & 5 \\
\hline Age & 80 & 80 & 61 & 81 & 80 \\
Sex & F & F & M & M & M \\
Dx & PDD & DLB & PDD & PD & NN \\
PMD & $5: 15$ & $5: 00$ & $5: 00$ & $4: 30$ & $7: 00$ \\
\hline
\end{tabular}

$D x$ diagnosis, $P D$ Parkinson's disease, $P D D$ Parkinson's disease dementia, $D L B$ dementia with Lewy bodies, $N N$ neurologically normal, $P M D$ postmortem delay 
with the $\operatorname{IgY}$ antibodies at a concentration of $0.5 \mu \mathrm{g} / \mathrm{ml}$. Detection was performed using a biotinylated secondary anti-chicken $(1.5 \mu \mathrm{g} / \mathrm{ml}$, Jackson ImmunoResearch Laboratories Inc.), followed by incubation with StreptavidinHRP (1:30, 3310-9, Mabtech AB, Nacka, Sweden). The signal was visualized using the NovaRed substrate kit (Vector Laboratories). The sections were counterstained with hematoxylin (Histolab, Gothenburg, Sweden), dehydrated and mounted with DPX (VWR, Stockholm, Sweden). As a negative control, sections were incubated with secondary antibody alone.

\section{Neuropathological Analysis of Mouse and Human Brain Tissue}

Two independent assessors analyzed immunohistochemically stained sections semi-quantitatively in a blinded manner. The intensity of the staining was scored on a predetermined scale of $0-3(0=$ no signal, $1=$ overall faint signal, orange/yellow-colored LB in human tissue, $2=$ overall positive signal, red-colored LB in human tissue, $3=$ very strong signal, dark red/brown-colored LB in human tissue), and scores were averaged. The differences between mouse and human brain were assessed by a twoway ANOVA and Bonferroni post hoc tests.

\section{Results}

\section{Characterization of Immunoglobulin Y Antibodies}

In order to determine the surface-exposed epitopes of alpha-synuclein, we generated 18 polyclonal IgY antibodies against short linear peptides spanning most of the alphasynuclein molecule (Fig. 1). We chose to generate chicken IgY antibodies because of the increased phylogenetic distance between chicken and humans compared to other mammalian species typically used for antibody production (e.g., rabbit) (Hadge and Ambrosius 1984). The sequence identity of chicken alpha-synuclein and human alphasynuclein is $86.7 \%$ compared to $95 \%$ between rabbits and humans, which could potentially increase the immunogenicity of the alpha-synuclein peptides. The antibodies were affinity purified against their respective immunizing peptide and showed similar reactivity against them as observed by indirect ELISA (Fig. 2a).

To probe the specificity of the antibodies further, they were used in an indirect ELISA against longer peptides covering different parts of alpha-synuclein (10-34, 32-50, 45-65, 91-115, 101-125, and 115-140) (Fig. 2b). Eight of the antibodies $(22-31,35-44,54-63,59-68,74-83$, 101-110, 121-130, and 126-135) also recognized peptides that did not contain their immunizing sequence and therefore were eliminated from the study.

\section{Indirect ELISA of In Vitro Generated Aggregated Species of Alpha-Synuclein}

First, we mapped the surface-exposed epitopes of recombinant monomeric and oligomeric alpha-synuclein (Fig. 3a). All antibodies recognized monomeric alphasynuclein, but 49-58 and 64-73 reacted to a lesser extent. The N-terminal antibody 1-10 reacted with oligomers, while 49-58 did not. In the mid-region, 64-73 was negative against oligomers and $79-88$ was positive. The C-terminal antibodies (90-140) all recognized oligomeric alpha-synuclein.

Point mutations in the alpha-synuclein (SNCA) gene enhance aggregation and cause early-onset PD or DLB (Polymeropoulos et al. 1997; Krüger et al. 1998; Conway et al. 2000; Zarranz et al. 2004; Greenbaum et al. 2005). We generated fibrils consisting of either wild-type (wt) protein or the three mutants (A30P, E46K and A53T) and analyzed them using indirect ELISA (Fig. 3b). The overall reaction pattern for the different fibrils was similar, where the antibody against $1-10$, as well as the C-terminal (i.e., 90-140) antibodies showed the highest signals. Overall, the strongest immunoreactivity was observed for wt and A30P fibrils, whereas the lowest signals were seen with the A53T fibrils.

Alpha-synuclein interacts with anionic phospholipids in the neuronal membrane, and the binding has been suggested to be facilitated by the N-terminal part of the protein (Davidson et al. 1998). To determine the lipid-binding ability of the various alpha-synuclein species and to discern the membrane-associated epitopes, an indirect
Fig. 1 Sequence of immunizing peptides and human alpha-synuclein with its three structural regions: the $\mathrm{N}$-terminus (1-60 red), the midregion (61-95 purple), and the C-terminus (96-140 blue) (Color figure online)

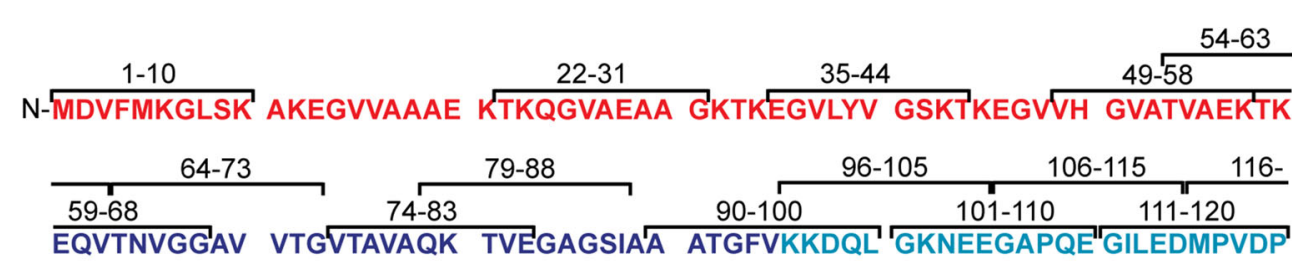

$\frac{-125 \quad 126-135}{121-130 \quad \frac{131-140}{\text { DNEAYEMPSE EGYQDYEPEA-C }}}$


Fig. 2 Indirect ELISA characterizing the generated antibodies. The immunizing peptides were coated onto a microtiter plate and analyzed with the corresponding antibody (a). Peptides of 19-26 amino acids were coated onto a plate and analyzed with the antibodies to further test their specificity. Underlined antibodies showed no crossreactivity and were selected for the following experiments (b). Error bars represent the standard error of the mean (SEM), and each experiment was performed three times with sample duplicates (Color figure online)
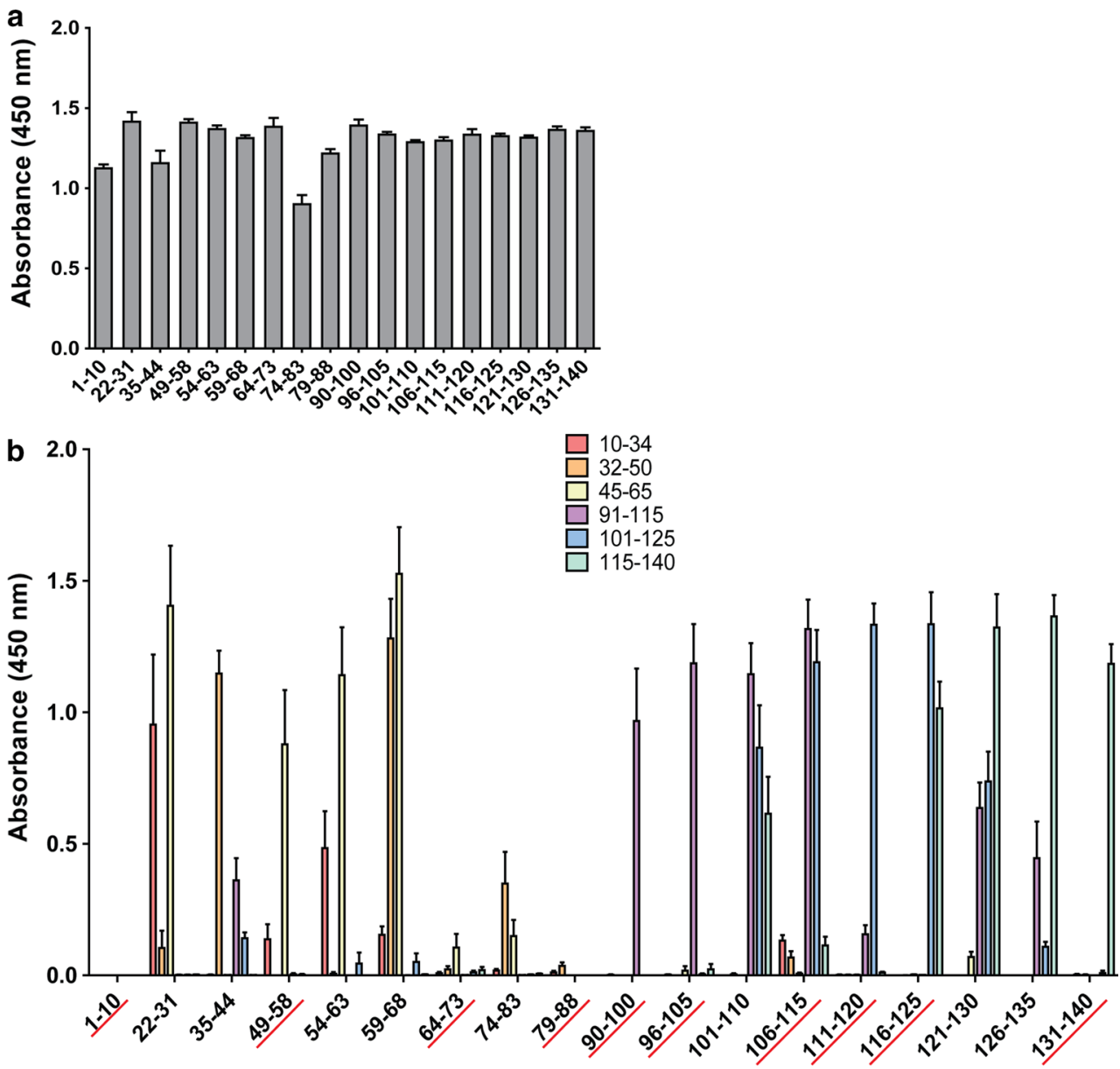

phospholipid ELISA was used. Monomeric and fibrillar (wt) alpha-synuclein were incubated on a plate pre-coated with phosphatidylserine, and the interaction was probed with the antibodies (Fig. 3c). Antibodies against the C-terminus (96-140) reacted with monomeric alpha-synuclein, and to a lesser extent fibrils, with the exception of the antibody 111-120 that reacted to fibrils equally well. In contrast, the antibodies against the $\mathrm{N}$-terminus and midregion (i.e., 1-95) did not react with monomers or fibrils (with the exception of 1-10 that recognized fibrils), indicating that this region of the molecule was indeed interacting with phosphatidylserine.

\section{Immunohistochemistry of Mouse and Human Brain}

Next, we wanted to analyze exposed epitopes of in vivo deposited alpha-synuclein aggregates by performing immunohistochemistry with the antibodies on formalinfixed and paraffin-embedded tissue sections of (Thy-1)$\mathrm{h}[\mathrm{A} 30 \mathrm{P}]$ alpha-synuclein transgenic mouse brain and sections from the substantia nigra of PD, PDD, and DLB patients. We performed a proteinase $\mathrm{K}$ treatment to digest non-fibrillar alpha-synuclein (Giasson et al. 2001; Miake et al. 2002; Neumann et al. 2002) and to ensure that the aggregates observed in both mouse and human tissue were comparable.

The (Thy-1)-h[A30P] alpha-synuclein transgenic mouse model presents cognitive decline at 12 months of age, whereas PD-like motor symptoms can be observed at 17 months (Kahle et al. 2000; Schell et al. 2009). Brain sections from four mice at or after onset of motor symptom were analyzed. Alpha-synuclein aggregates could be observed in the cerebellum, mid-brain, pons, medulla and to a lesser extent in the cortex. Four types of alpha-synuclein aggregates could be distinguished: (1) small, dotted grain-like intracellular aggregates, which were the most abundant in all brain regions; (2) Lewy-neurite-like elongated structures, which sometimes accompanied the grainlike staining; (3) Lewy body-like inclusions, which could occasionally be observed, most frequently in the cerebellum, and (4) diffuse nuclear and cytoplasmic accumulation of alpha-synuclein, which was predominantly observed in the cerebellum and mid-brain (Fig. 4). The highest immunoreactivity was observed with the C-terminal epitope $96-105$. The N-terminal antibody $1-10$ and $\mathrm{C}$-terminal antibodies 90-100, 106-115, 111-120, 116-125, and 

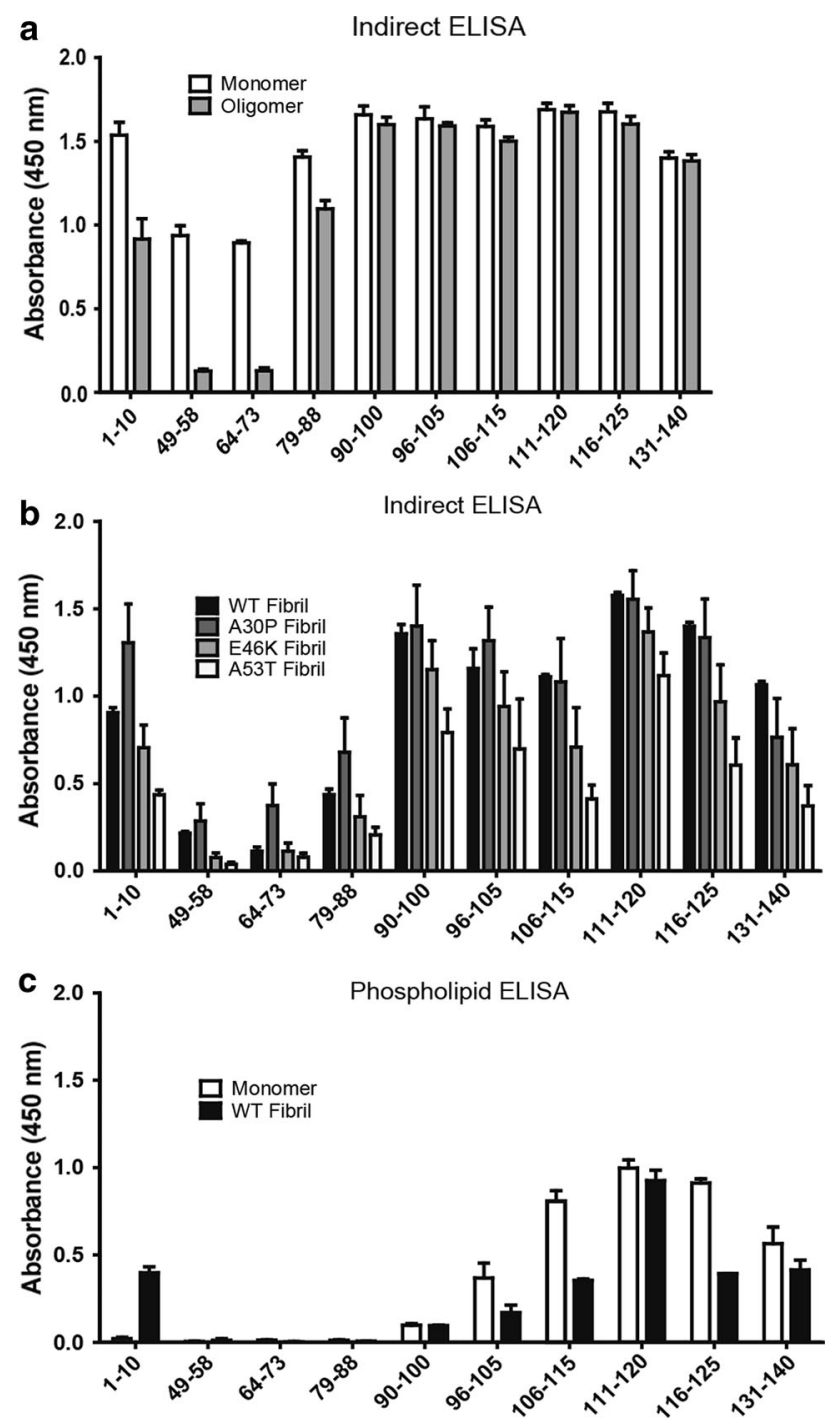

Fig. 3 Indirect ELISA. The antibodies were used to analyze surfaceexposed epitopes of monomeric and oligomeric alpha-synuclein (a) and wt, A30P, E46K, and A53T alpha-synuclein fibrils (b). Monomeric and fibrillar alpha-synuclein were incubated in a precoated phosphatidylserine microtiter plate for an indirect phospholipid ELISA (c). The error bars represent the SEM. Each experiment was performed three times (except in the phospholipid ELISA; $n=2$ ) with sample duplicates

131-140 also stained the described structures, with variable intensities. The antibody against $131-140$, in particular, showed less immunoreactivity. No staining was observed with the antibodies 49-58 and 64-73, and very faint staining with $79-88$ could be observed.

In the human PD, DLB, and PDD brain tissue, 1-10 and the C-terminal antibodies 111-120 and 116-125 showed the highest reactivity and stained both Lewy bodies and Lewy neurites (Fig. 5). The rest of the C-terminal antibodies (90-100, 96-105, 106-115, and 131-140) produced a weaker staining of inclusions. No immunoreactivity of
Lewy body pathology was detected with antibodies recognizing epitopes $49-58,64-73$, and 79-88, which correspond to the latter part of the $\mathrm{N}$-terminus and mid-region of alpha-synuclein. No differences were observed amongst tissue from patients with different alpha-synucleinopathies (i.e., PD, DLB, and PDD).

The staining was semi-quantitatively analyzed by visual scoring between 0 and 3 by two blinded independent assessors (Fig. 6). Significant differences were observed between the intensity of the staining of the transgenic mice and the diseased human brains by the 96-105, 116-125, and 131-140 antibodies.

\section{Discussion}

In Lewy body disorders, the alpha-synuclein protein loses its native structure and aggregates as insoluble Lewy bodies and Lewy neurites (Spillantini et al. 1997). The fibrillation of alpha-synuclein has been studied to a great extent in vitro. However, a wide range of heterogeneous structures is formed during the aggregation of recombinant alpha-synuclein, and it is uncertain how well they reflect the aggregates formed in vivo. With the aim to identify similarities and differences of in vitro and in vivo formed alpha-synuclein aggregates, we generated 18 polyclonal antibodies against peptides covering most of the alphasynuclein sequence. However, when the specificity of the antibodies was tested, we observed that eight of the antibodies also reacted with alpha-synuclein epitopes outside their immunizing sequence and hence they were omitted from the study due to the unspecific binding. In previous studies (Giasson et al. 2000; Duda et al. 2002), antibodies recognizing linear epitopes have been used to characterize alpha-synuclein aggregates, but compared to the present investigation, fewer epitopes were studied and mostly human material was analyzed.

In agreement with the structure of a disordered protein, recombinant monomeric alpha-synuclein reacted with all the antibodies; however, the 1-10 and all C-terminal antibodies showed higher reactivity. In vitro generated fibrils of alpha-synuclein have been shown to contain a beta-sheet-rich core (Heise et al. 2005; Chen et al. 2007), spanning approximately residues 35-96 as observed by nuclear magnetic resonance spectroscopy, although the exact length of the core varies amongst studies (Vilar et al. 2008; Tuttle et al. 2016). In agreement with this model, the fibrils analyzed by the ELISA showed that epitopes 49-58 and 64-73 were not accessible, and presumably hidden in the core of the fibril structure. The exposed epitopes in the oligomers were similar to those in the fibril, with the exception of 79-88, which was positive in the oligomers but only weakly reactive in the fibrils. The alpha-synuclein 


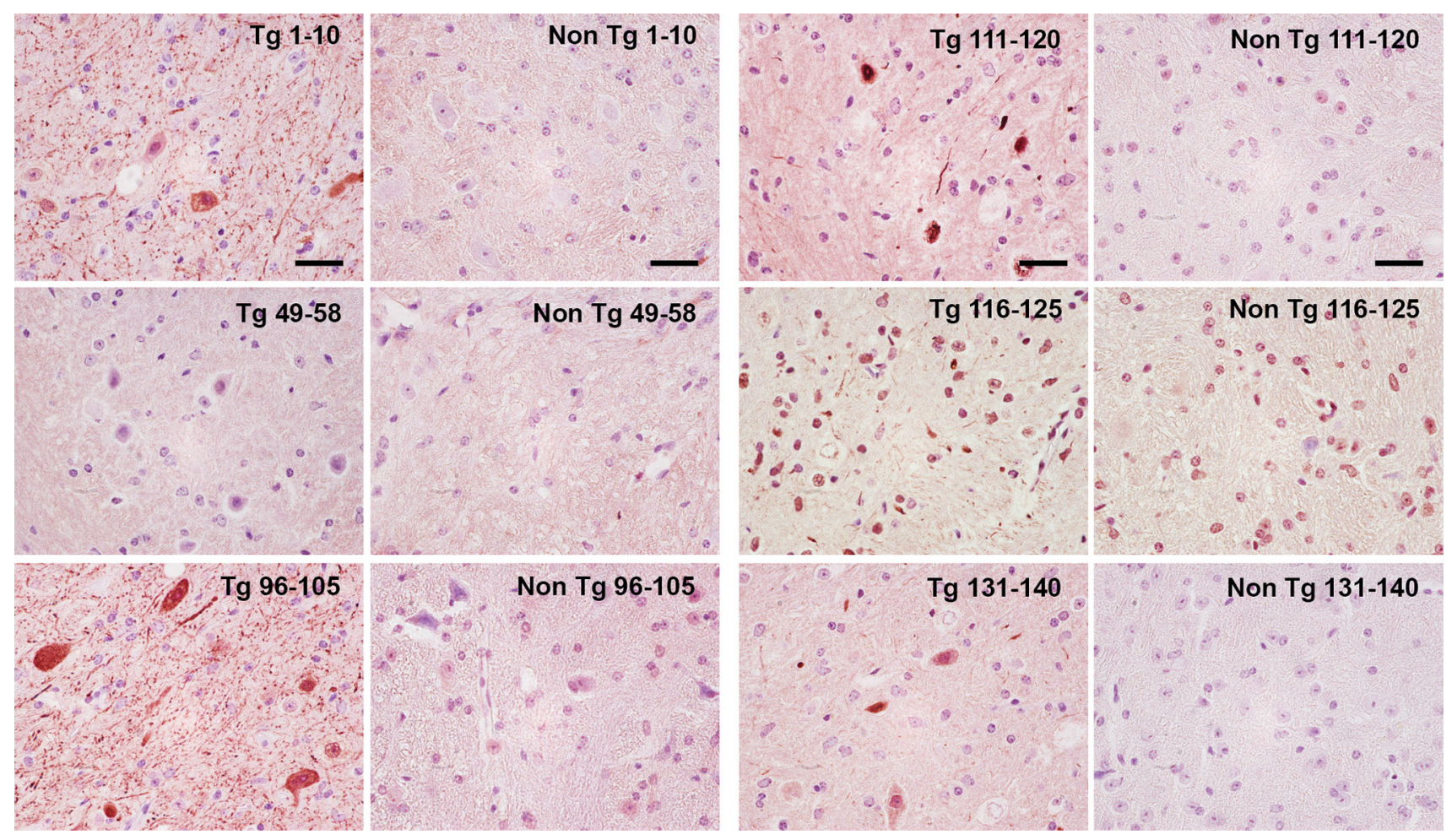

Fig. 4 Representative images of immunohistochemical staining of (Thy-1)-h[A30P] alpha-synuclein transgenic (Tg) mouse cerebellum. Non-Tg (non-transgenic). Scale bar $20 \mu \mathrm{m}$
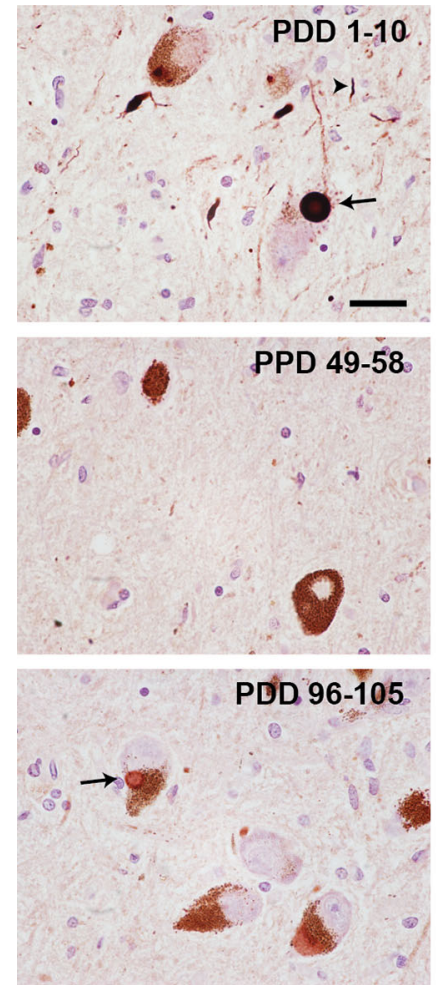
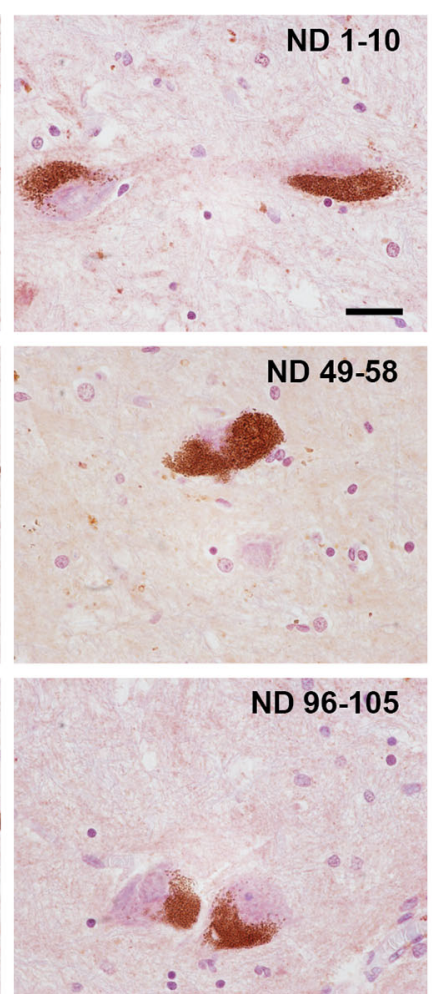
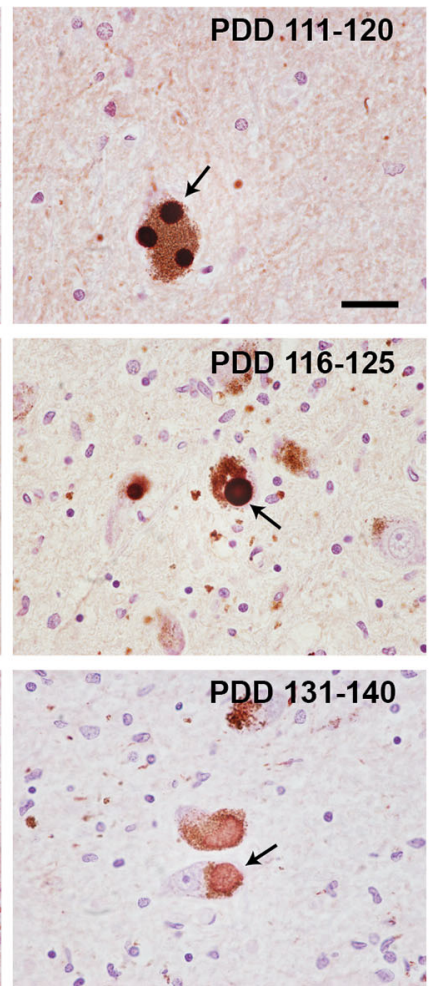
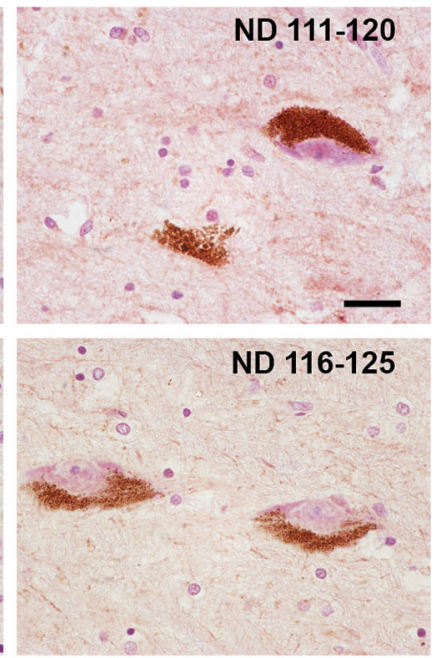

ND. $131-140$

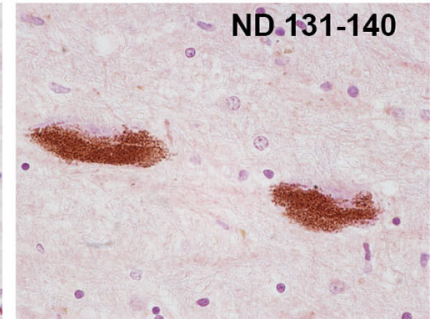

Fig. 5 Representatitve images of immunohistochemichal staining of substantia nigra brain tissue from a PDD patient and non-diseased (ND) brain. Arrows indicate Lewy bodies and arrowheads indicate Lewy neurites. Scale bar $20 \mu \mathrm{m}$ 


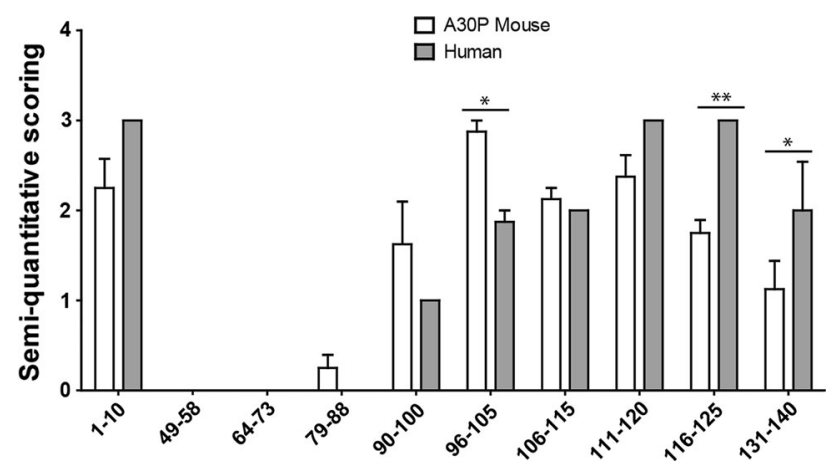

Fig. 6 Semi-quantitative assessment (0-3) of the intensity of the immunostaining of four (Thy-1)-h[A30P] alpha-synuclein transgenic mouse brains and four alpha-synucleinopathy patients. ${ }^{*} P<0.05$; $* * P<0.001$, two-way ANOVA followed by Bonferroni post hoc test, error bars represent the standard error of the mean (SEM)

mutations A30P, E46K, and A53T have been shown to oligomerize faster than the wt protein in vitro (Conway et al. 2000; Greenbaum et al. 2005). Furthermore, atomic force microscopy studies indicate that the fibrils generated with these alpha-synuclein mutations may exhibit structural heterogeneity compared to fibrils formed by wt protein (van Raaij et al. 2006). However, in the current study, the surface-exposed epitopes of A30P, E46K, and A53T fibrils did not differ to any large degree; suggesting that although mutant alpha-synuclein may aggregate faster than wt protein, the fibrils formed exhibit a similar structure.

Alpha-synuclein exists in equilibrium between a cytosolic and a membrane bound state in vivo (Davidson et al. 1998). The seven imperfect repeats (KTKEGV) located in the N-terminus exhibit a variation in hydrophobicity that is typical of the amphipathic lipidbinding $\alpha$-helical domains of apolipoproteins (George et al. 1995). As lipid binding has been suggested to be an important factor for the physiological function of alphasynuclein, we used a phospholipid ELISA assay to probe which epitopes interact with phospholipids in different molecular species of alpha-synuclein. We chose to use a lipid ELISA assay based on phosphatidylserine due to the fact that this is a common anionic lipid of eukaryotic cellular membranes and is known to bind to alpha-synuclein (Davidson et al. 1998; Pranke et al. 2011; Zarbiv et al. 2014). For monomeric alpha-synuclein, only C-terminal epitopes (i.e., 96-140) were accessible, and this indicates that the $\mathrm{N}$-terminus and the mid-region of the protein were indeed lipid bound and hence not available for antibody binding. Interestingly, wt fibrils also showed a strong binding to phosphatidylserine, and similar to monomeric protein, the C-terminus was most accessible to antibody binding. This suggests that the $\mathrm{N}$-terminus and the midregion (i.e., 1-95) are responsible for the interaction with phosphatidylserine, which is consistent with the previously mentioned lipid-binding domain of alpha-synuclein. The surprising finding that the $\mathrm{N}$-terminal part of the fibrils (i.e., 1-10) was somewhat accessible could most likely be explained by the fact that as several protofilaments constitute a single fibril, not all their $\mathrm{N}$-terminal parts need to be associated with lipids in order to facilitate binding. It should be noted that in the phospholipid ELISA, the phosphatidylserine molecules are forming a planar layer, and since alpha-synuclein is highly sensitive to membrane curvature (Middleton and Rhoades 2010), the exposed epitopes could potentially vary when bound to cellular membranes and lipid vesicles.

To the best of our knowledge, no study has compared alpha-synuclein inclusions in human and mice brain tissue. Therefore, we used our novel antibodies to analyze the alpha-synuclein immunoreactivity in the brain of a tg mouse model overexpressing human A30P mutant alphasynuclein (Kahle et al. 2000), as well as in substantia nigra specimens from patients with alpha-synucleinopathies. The proteinase $\mathrm{K}$ treatment is routinely used to assess fibrillar alpha-synuclein in tissue (Kramer and Schulz-Schaeffer 2007; Tanji et al. 2010), and it allows us to observe structures that are similar in compactness and morphology. In the alpha-synuclein transgenic mice, the most abundant pathology was found in the brainstem (Neumann et al. 2002; Freichel et al. 2007), where small aggregates were observed, only occasionally accompanied by larger, more compact inclusions, similar to those found in human tissue. Nuclear and cytoplasmic staining of neurons was also frequently detected with the most reactive antibodies. In both human and mouse tissue, the strongest reactivity was observed with antibodies against the 1-10 epitope in the $\mathrm{N}$-terminus and the $\mathrm{C}$-terminus. However, we found differences in the intensity of the staining between these tissue types for antibodies 96-105, 116-125, and 131-140. Taken together, these findings indicate that there might be structural differences between the aggregates formed by human alpha-synuclein in mice and human brains. Generally, a greater variability of the overall amount of alpha-synuclein pathology was observed amongst the mice, but it did not affect the general staining pattern of the antibodies.

A previous study using monoclonal antibodies that recognized epitopes between 87 and 140 and two polyclonal antibodies that recognized 2-12 (SNL-4) and 104-119 (SNL-1) showed strong staining of Lewy bodies and neurites in the substantia nigra of PD and DLB patients (Giasson et al. 2000). The results with the SNL-4 antibody are comparable to the observations of the 1-10 antibody in the present study and the SNL-1 is similar to the antibody 111-120, which recognized abundant Lewy body pathology. Additionally, Kovacs et al. (2012) generated and characterized a monoclonal antibody (5G4), which specifically recognizes amino acids $44-57$ and strongly 
labels alpha-synuclein pathology in human brain tissue. In contrast, our antibody against epitope 49-58, which recognizes a similar epitope, failed to detect any alpha-synuclein pathology in both the mice and the human tissue. This suggests that the lack of reaction with one of the $\operatorname{IgY}$ antibodies does not necessarily mean that the entire sequence used to produce that antibody is hidden. The difference in immunoreactivity could most likely be explained by the fact that 5G4 recognizes a slightly different epitope.

Taken together, the present study shows that some parts of the protein always appear to be exposed on the surface; specifically, the beginning of the $\mathrm{N}$-terminus and the entirety of the C-terminus were recognized by the $\operatorname{IgY}$ antibodies in both in vitro monomeric and aggregated samples, as well as in brain sections. On the other hand, with the exception of the native protein, most of the midregion of aggregated alpha-synuclein was consistently occluded in aggregated forms, which is in agreement with the previously mentioned fibril core. However, the finding that C-terminal epitopes were exposed differently in tg mice and human tissue also suggests that subtle structural differences can exist in the alpha-synuclein aggregation species formed in different organisms.

Acknowledgements The work was supported financially by Grants from Swedish Research Council (2011-4519), Marianne and Marcus Wallenberg Foundation, Swedish Alzheimer Foundation, Swedish Parkinson Foundation, Uppsala Berzelii Technology Center for Neurodiagnostics, Swedish Brain Foundation, Swedish Society of Medicine, Lennart and Christina Kalén, Stohne's Foundation, Åhlén Foundation, and Swedish Brain Power. We thank Cindy Boden (DZNE Tübingen) for the preparation of mouse brain sections.

\section{Compliance with Ethical Standards}

Conflict of interest The authors declare no competing financial interests.

Open Access This article is distributed under the terms of the Creative Commons Attribution 4.0 International License (http://creative commons.org/licenses/by/4.0/), which permits unrestricted use, distribution, and reproduction in any medium, provided you give appropriate credit to the original author(s) and the source, provide a link to the Creative Commons license, and indicate if changes were made.

\section{References}

Abeliovich A, Schmitz Y, Fariñas I et al (2000) Mice lacking alphasynuclein display functional deficits in the nigrostriatal dopamine system. Neuron 25:239-252. doi:10.1016/S08966273(00)80886-7

Appel-Cresswell S, Vilarino-Guell C, Encarnacion M et al (2013) Alpha-synuclein p. H50Q, a novel pathogenic mutation for Parkinson's disease. Mov Disord 28:811-813. doi:10.1002/mds. 25421

Burré J, Sharma M, Tsetsenis T et al (2010) Alpha-synuclein promotes SNARE-complex assembly in vivo and in vitro. Science 329:1663-1667. doi:10.1126/science.1195227
Chen M, Margittai M, Chen J, Langen R (2007) Investigation of alpha-synuclein fibril structure by site-directed spin labeling. J Biol Chem 282:24970-24979. doi:10.1074/jbc.M700368200

Conway KA, Lee S, Rochet J et al (2000) Acceleration of oligomerization, not fibrillization, is a shared property of both alpha-synuclein mutations linked to early-onset Parkinson's disease: implications for pathogenesis and therapy. Proc Natl Acad Sci USA 97:571-576

Danzer KM, Haasen D, Karow AR et al (2007) Different species of alpha-synuclein oligomers induce calcium influx and seeding. J Neurosci 27:9220-9232. doi:10.1523/JNEUROSCI.2617-07. 2007

Davidson WS, Jonas A, Clayton DF, George JM (1998) Stabilization of alpha-synuclein secondary structure upon binding to synthetic membranes. J Biol Chem 273:9443-9449. doi:10.1074/jbc.273. 16.9443

Duda JE, Giasson BI, Mabon ME et al (2002) Novel antibodies to synuclein show abundant striatal pathology in Lewy body diseases. Ann Neurol 52:205-210. doi:10.1002/ana.10279

Freichel C, Neumann M, Ballard T et al (2007) Age-dependent cognitive decline and amygdala pathology in $\alpha$-synuclein transgenic mice. Neurobiol Aging 28:1421-1435. doi:10.1016/ j.neurobiolaging.2006.06.013

George JM, Jin H, Woods WS, Clayton DF (1995) Characterization of a novel protein regulated during the critical period for song learning in the zebra finch. Neuron 15:361-372

Giasson BI, Jakes R, Goedert M et al (2000) A panel of epitopespecific antibodies detects protein domains distributed throughout human alpha-synuclein in Lewy bodies of Parkinson's disease. J Neurosci Res 59:528-533. doi:10.1002/(SICI)10974547(20000215)59:4<528:AID-JNR8>3.0.CO;2-0

Giasson BI, Murray IV, Trojanowski JQ, Lee VM (2001) A hydrophobic stretch of 12 amino acid residues in the middle of alpha-synuclein is essential for filament assembly. J Biol Chem 276:2380-2386. doi:10.1074/jbc.M008919200

Goedert M (2001) Parkinson's disease and other $\alpha$-synucleinopathies. Clin Chem Lab Med 39:308-312. doi:10.1515/ CCLM.2001.047

Greenbaum EA, Graves CL, Mishizen-Eberz AJ et al (2005) The E46 K mutation in alpha-synuclein increases amyloid fibril formation. J Biol Chem 280:7800-7807. doi:10.1074/jbc. M411638200

Hadge D, Ambrosius H (1984) Evolution of low molecular weight immunoglobulins-IV. IgY-like immunoglobulins of birds, reptiles and amphibians, precursors of mammalian $\operatorname{IgA}$. Mol Immunol 21:699-707. doi:10.1016/0161-5890(84)90022-1

Heise H, Hoyer W, Becker S et al (2005) Molecular-level secondary structure, polymorphism, and dynamics of full-length alphasynuclein fibrils studied by solid-state NMR. Proc Natl Acad Sci USA 102:15871-15876. doi:10.1073/pnas.0506109102

Ibáñez P, Bonnet A-M, Débarges B et al (2004) Causal relation between $\alpha$-synuclein locus duplication as a cause of familial Parkinson's disease. Lancet 364:1169-1171. doi:10.1016/S01406736(04)17104-3

Kahle PJ, Neumann M, Ozmen L et al (2000) Subcellular localization of wild-type and Parkinson's disease-associated mutant alphasynuclein in human and transgenic mouse brain. J Neurosci 20:6365-6373

Karpinar DP, Balija MBG, Kügler S et al (2009) Pre-fibrillar alphasynuclein variants with impaired beta-structure increase neurotoxicity in Parkinson's disease models. EMBO J 28:3256-3268. doi:10.1038/emboj.2009.257

Kovacs GG, Wagner U, Dumont B et al (2012) An antibody with high reactivity for disease-associated $\alpha$-synuclein reveals extensive brain pathology. Acta Neuropathol 124:37-50. doi:10.1007/ s00401-012-0964-x 
Kramer ML, Schulz-Schaeffer WJ (2007) Presynaptic alpha-synuclein aggregates, not Lewy bodies, cause neurodegeneration in dementia with Lewy bodies. J Neurosci 27:1405-1410. doi:10. 1523/JNEUROSCI.4564-06.2007

Krüger R, Kuhn W, Müller T et al (1998) Ala30Pro mutation in the gene encoding $\alpha$-synuclein in Parkinson's disease. Nat Genet 18:106-108. doi:10.1038/ng0298-106

Lesage S, Anheim M, Letournel F et al (2013) G51D $\alpha$-synuclein mutation causes a novel Parkinsonian-pyramidal syndrome. Ann Neurol. doi:10.1002/ana.23894

Miake H, Mizusawa H, Iwatsubo T, Hasegawa M (2002) Biochemical characterization of the core structure of alpha-synuclein filaments. J Biol Chem 277:19213-19219. doi:10.1074/jbc. M110551200

Middleton ER, Rhoades E (2010) Effects of curvature and composition on $\alpha$-synuclein binding to lipid vesicles. Biophys $\mathrm{J}$ 99:2279-2288. doi:10.1016/j.bpj.2010.07.056

Näsström T, Fagerqvist T, Barbu $M$ et al (2011) The lipid peroxidation products 4-oxo-2-nonenal and 4-hydroxy-2-nonenal promote the formation of $\alpha$-synuclein oligomers with distinct biochemical, morphological, and functional properties. Free Radic Biol Med 50:428-437. doi:10.1016/j.freeradbiomed.2010. 11.027

Nemani VM, Lu W, Berge V et al (2010) Increased expression of alpha-synuclein reduces neurotransmitter release by inhibiting synaptic vesicle reclustering after endocytosis. Neuron 65:66-79. doi:10.1016/j.neuron.2009.12.023

Neumann M, Kahle PJ, Giasson BI et al (2002) Misfolded proteinase $\mathrm{K}$-resistant hyperphosphorylated alpha-synuclein in aged transgenic mice with locomotor deterioration and in human alphasynucleinopathies. J Clin Investig 110:1429-1439. doi:10.1172/ JCI200215777

Outeiro TF, Putcha P, Tetzlaff JE et al (2008) Formation of toxic oligomeric alpha-synuclein species in living cells. PLoS ONE 3:e1867. doi:10.1371/journal.pone.0001867

Papp MI, Kahn JE, Lantos PL (1989) Glial cytoplasmic inclusions in the CNS of patients with multiple system atrophy (striatonigral degeneration, olivopontocerebellar atrophy and Shy-Drager syndrome). J Neurol Sci 94:79-100. doi:10.1016/0022510X(89)90219-0

Pasanen P, Myllykangas L, Siitonen M et al (2014) A novel $\alpha$ synuclein mutation A53E associated with atypical multiple system atrophy and Parkinson's disease-type pathology. Neurobiol Aging 35:2180.e1-2180.e5. doi:10.1016/j.neurobiolaging. 2014.03.024
Polymeropoulos MH, Lavedan C, Leroy E et al (1997) Mutation in the alpha-synuclein gene identified in families with Parkinson's disease. Science 276:2045-2047. doi:10.1126/science.276.5321. 2045

Pranke IM, Morello V, Bigay J et al (2011) $\alpha$-Synuclein and ALPS motifs are membrane curvature sensors whose contrasting chemistry mediates selective vesicle binding. J Cell Biol 194:89-103. doi:10.1083/jcb.201011118

Schell H, Hasegawa T, Neumann M, Kahle PJ (2009) Nuclear and neuritic distribution of serine-129 phosphorylated $\alpha$-synuclein in transgenic mice. Neuroscience 160:796-804. doi:10.1016/j. neuroscience.2009.03.002

Singleton AB, Farrer M, Johnson J et al (2003) Alpha-synuclein locus triplication causes Parkinson's disease. Science 302:841. doi:10. 1126/science. 1090278

Spillantini MG, Schmidt ML, Lee VMY et al (1997) Alpha-synuclein in Lewy bodies. Nature 388:839-840. doi:10.1038/42166

Spillantini MG, Crowther RA, Jakes R et al (1998) Alpha-synuclein in filamentous inclusions of Lewy bodies from Parkinson's disease and dementia with Lewy bodies. Proc Natl Acad Sci USA 95:6469-6473. doi:10.1073/pnas.95.11.6469

Tanji K, Mori F, Mimura J et al (2010) Proteinase K-resistant alphasynuclein is deposited in presynapses in human Lewy body disease and A53T alpha-synuclein transgenic mice. Acta Neuropathol 120:145-154. doi:10.1007/s00401-010-0676-z

Tuttle MD, Comellas G, Nieuwkoop AJ et al (2016) Solid-state NMR structure of a pathogenic fibril of full-length human $\alpha$-synuclein. Nat Struct Mol Biol 23:1-9. doi:10.1038/nsmb.3194

van Raaij ME, Segers-Nolten IMJ, Subramaniam V (2006) Quantitative morphological analysis reveals ultrastructural diversity of amyloid fibrils from alpha-synuclein mutants. Biophys J 91:L96L98. doi:10.1529/biophysj.106.090449

Vilar M, Chou H, Lührs T (2008) The fold of $\alpha$-synuclein fibrils. Proc Natl Acad Sci USA. doi:10.1073/pnas.0712179105

Winner B, Jappelli R, Maji SK et al (2011) In vivo demonstration that $\alpha$-synuclein oligomers are toxic. Proc Natl Acad Sci USA 108:4194-4199. doi:10.1073/pnas.1100976108

Zarbiv Y, Simhi-Haham D, Israeli E et al (2014) Lysine residues at the first and second KTKEGV repeats mediate $\alpha$-synuclein binding to membrane phospholipids. Neurobiol Dis 70:90-98. doi:10.1016/j.nbd.2014.05.031

Zarranz JJ, Alegre J, Gómez-Esteban JC et al (2004) The new mutation, E46 K, of alpha-synuclein causes Parkinson and Lewy body dementia. Ann Neurol 55:164-173. doi:10.1002/ana.10795 